$\begin{array}{ll}\text { TITLE: } & \text { ELECTROKINETIC DENSIFICATION OF } \\ & \text { COAL FINES IN WASTE PONDS }\end{array}$

STUDENT: Timothy Johnson, PhD Candidate, Chemical-Engineering (tjohn@u.washington.edu) Sheryl Filby, Summer Intern (Gustavus Adolphus College)

INSTITUTION: University of Washington

Department of Chemical Engineering, Box 351750

Seattle, WA $98195-1750$

Phone: (206) 543-2250

Fax: $\quad$ (206) $543-3778$

GRANT NO.: DE-FG22-95PC95209

PERIOD OF PERFORMANCE: June 1997 to April 1998

\title{
I. ABSTRACT
}

OBJECTIVE: The objective of this research is to demonstrate that electrokinetics can be used to remove colloidal coal and mineral particles from coal-washing ponds and lakes without the addition of chemical additives such as salts and polymeric flocculants. In this experimental and analytical study we elucidate the transport processes that control the rate of concentrated colloidal particle removal, demonstrate the process on a laboratory scale, and develop the scale-up laws needed to design commercial-scale processes. We are also addressing the fundamental problems associated with particle-particle interactions (electrical and hydrodynamic), the effects of particle concentration on the applied electric field, the electrochemical reactions that occur at the electrodes, and the prediction of power requirements.

\section{WORK DONE AND CONCLUSIONS:}

It has been demonstrated that heavily contaminated water from a coal-washing facility in Centralia, Washington can be clarified by applying an electric field to the colloidal suspension. The Centralia Mining Company, a subsidiary of PacificCorp, provides coal for two $665 \mathrm{MW}$ coal-burning power plants operated by PacificCorp Power Supply. Water is used to wash the coal during beneficiation to remove fine coal dust and clay particles, and the resulting suspension has a solids content as high as $1 \%$. The colloidal particles typically have mean diameters of $1.8 \mu \mathrm{m}$ and zeta potentials of $\sim-25 \mathrm{mV}$, so electrokinetic treatment is feasible.

The research focus to date has been on determining the effects of suspended solids and electrolyte concentration on the rate of water clarification and the resulting power requirement. It has been determined that an increase in the suspended solids concentration decreases the asymptotic power levels, but increases the suspension conductivity and the time necessary for clarification. Similarly, an increase in the electrolyte concentration decreases the asymptotic power levels, but increases the suspension conductivity and clarification time.

Additional research efforts have been focused on the design, construction, and testing of an apparatus for continuous electrophoretic sedimentation of colloidal contaminants. A frontal view of the apparatus is shown in Figure 1. This apparatus is based on a previously designed batch system which contains rotating carbon rods for the anode. The anode rotation was found to be necessary so that the sedimenting particles may be cleaned from the surfaces of the electrodes. The process was made continuous by adding the contaminated water near the anode and removing the clarified water near the cathode. An outlet line for 
the removal of accumulated sediment was also incorporated in the sump area below the anode. Preliminary experiments have been successful with flowrates near $40 \mathrm{ml} / \mathrm{min}$.

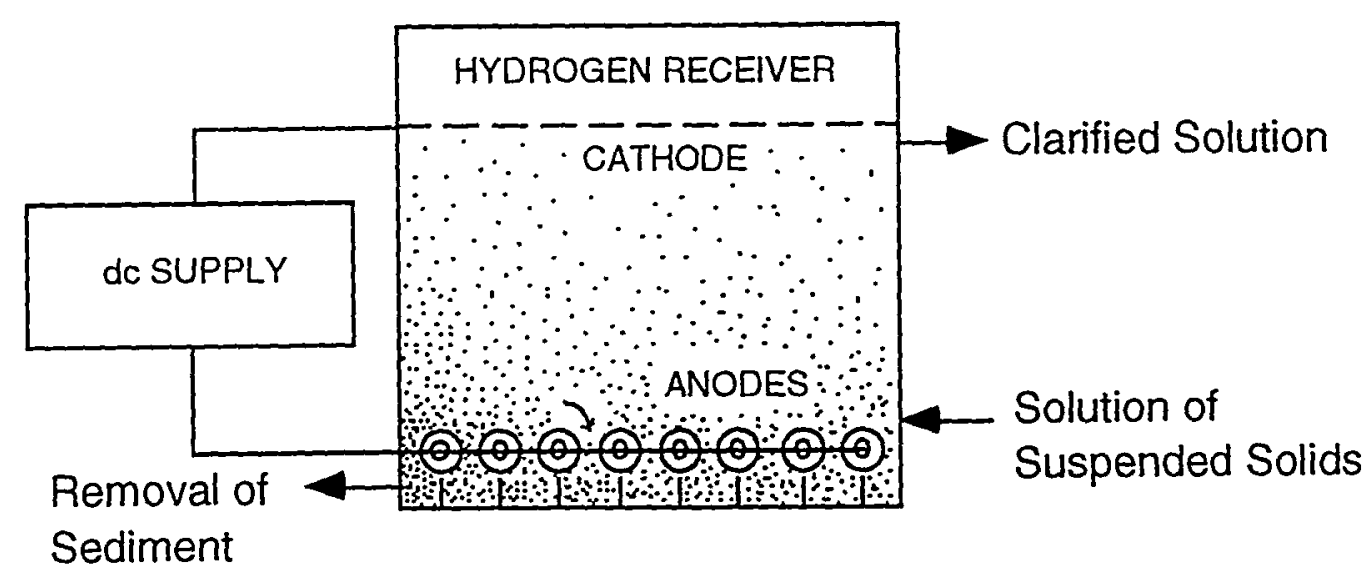

Figure 1. The continuous electrophoretic cell used for sedimentation.

SIGNIFICANCE TO FOSSIL ENERGY PROGRAM: Coal-washing facilities represent a significant source of water pollution in coal-producing areas. The removal of coal and mineral fines by electrokinetic methods produces clean process water which can be recycled without the addition of flocculating agents, salts and other chemicals. Thus, there is no detriment to wildlife or water supplies if discharged into natural streams or groundwater. The process designed has several advantages including simplicity, potential for scale-up and low power requirements.

\section{PLANS FOR THE COMING YEAR:}

- Complete theoretical work on the electrophoretic motion of concentrated aqueous colloidal suspensions.

- Compare predicted sedimentation rates and power requirements with laboratory data to test the model for scale-up to commercial systems.

- Determine the effect of the clay/coal concentration ratio on sedimentation rates and extent of separation.

- Compare the measured time-dependent local electric field with theoretical calculations.

\section{HIGHLIGHT ACCOMPLISHMENTS}

- A novel continuous electrokinetic system has been designed which incorporates rotating anodes to prevent fouling and increase the degree and rate of separation.

- Determined that increasing the suspended solids concentration or the electrolyte concentration may decrease power levels, but increases the time necessary for clarification.

- Preliminary numerical studies relating to the rate of electrophoretic sedimentation along with the power requirements have been carried out.

\section{ARTICLES AND PRESENTATIONS}

Two presentations of research results to the scientific staff of PacificCorp Power Supply to develop interaction with the industry. A paper on the analysis of electrophoretic motion in concentrated suspensions is in preparation and another on experimental is planned. 


\section{DISCLAIMER}

This report was prepared as an account of work sponsored by an agency of the United States Government. Neither the United States Government nor any agency thereof, nor any of their employees, make any warranty, express or implied, or assumes any legal liability or responsibility for the accuracy, completeness, or usefulness of any information, apparatus, product, or process disclosed, or represents that its use would not infringe privately owned rights. Reference herein to any specific commercial product, process, or service by trade name, trademark, manufacturer, or otherwise does not necessarily constitute or imply its endorsement, recommendation, or favoring by the United States Government or any agency thereof. The views and opinions of authors expressed herein do not necessarily state or reflect those of the United States Government or any agency thereof. 


\section{DISCLAIMER}

Portions of this document may be illegible in electronic image products. Images are produced from the best available original document. 


$$
\text { GEFyza } 9500 \text { prom }
$$

A Report to the University Coal Research (UCR) Internship Program

by

Gail R. Furches

August 10, 1996

Research Project Title: Electrokinetic Removal of Colloidal Coal Fines from Process Water

\section{ACKNOWLEDGMENT}

Participant: Gail Furches

Host Institution: University of Washington

Department of Chemical Engineering, Box 351750

Seattle, WA 98195-1750

Host Advisor: Professor E. James Davis

Graduate Student: Timothy Johnson

\section{ABSTRACT}

Preliminary studies of the removal of coal and mineral fines from the contaminated process water of a coal-processing facility in Centralia, WA were performed to assess the feasibility of electrokinetic removal of such colloidal particles from aqueous suspensions. A laboratory-scale tank has been designed, constructed and instrumented to measure the rate of sedimentation of the colloidal particles as a function of the applied electric field. Contaminated water from a coal mine's preparation facility associated with a coal-fired power generation plant near Centralia, WA was collected and used in the laboratory experiments. The colloidal properties (zeta potential, particle size distribution, total suspended solids) of the fine particles were measured, and some information on the water chemistry and electrochemistry was obtained. Observations of the sedimentation of the colloidal particles under the influence of the electric field indicated that electrokinetic removal of the particles is feasible.

\section{OBJECTIVE}

The objective of this research is to demonstrate that electrokinetic techniques can be used to remove colloidal coal and mineral particles from the contaminated water resulting from coal washing and beneficiation. In addition, the scale-up laws will be formulated to permit laboratory results to be applied and extrapolated to large-scale processes.

\section{BACKGROUND}

Colloidal particles are particles with dimensions smaller than a few micrometers $(\mu \mathrm{m})$. Suspended in water, such small particles undergo Brownian motion and remain in 
suspension. Conventional sewage treatment methods agglomerate or flocculate the colloidal contaminants by chemical treatment so that gravitational sedimentation occurs. This usually involves the addition of salts such as alum (aluminum sulfate) and/or polymeric additives. The Centralia Power Plant in Centralia, WA, which is of particular interest in this research, consists of two 665 megawatt coal-burning units. The coalpreparation facility associated with the power plant spends $\$ 30,000$ per year for llocculation chemicals (aluminum sulfate and Calgon WT-2354) to treat the waste water.

This research project explores an approach to the removal of colloidal fines from the process water while in the system loop which does not require the use of costly chemical additives. The separation process of interest involves electrokinetics, the science of charged-particle motion in an electrical field. The surfaces of sand, coal, clay and other mineral particles become charged in the presence of water. At near neutral $\mathrm{pH}$ the particles are usually negatively charged. In this case, cations in the water are attracted to the vicinity of the surface resulting in an electrical double layer consisting of the bound surface charges and the mobile cations. When an external electrical field is applied to the suspension of particles they will move in the electrical field. This phenomenon is called electrophoresis.

Since the colloidal particles of the same type have the same polarity, they do not readily agglomerate, for they electrostatically repel each other. The function of chemical additives is either to collapse the electrical double layer (using alum) or to provide a bridge between particles (using polymers) to accomplish flocculation.

In 1921 Smoluchowski developed the first theoretical analysis of electrophoresis. His approximation for the electrophoretic velocity $v_{E}$ is

$$
v_{E}=\frac{\varepsilon_{0} D \zeta}{\mu} E,
$$

in which $\varepsilon_{0}$ is the permittivity of free space, $D$ is the dielectric constant of the fluid, $\mu$ is its viscosity, $\mathrm{E}$ is the applied electric field, and $\zeta$ is the zeta potential. The zeta potential is related to the surface charge on the particle, and is usually determined by direct measurement of the velocity of a particle in a known electric field.

The Smoluchowski equation is only valid for a particle in a large expanse of lluid and for thin electric double layers. Gouy and Chapman analyzed the diffuse double layer, and according to their theory the double layer thickness is given by

$$
\delta=\sqrt{\frac{\varepsilon_{0} \mathrm{DRT}}{2000 \mathrm{~F}^{2} \mathrm{I}}},
$$

where $R$ is the gas constant, $T$ is the temperature, $F$ is Faraday's constant ( $F=96485$ coulombs), and $I$ is the ionic strength in moles per liter defined by

$$
I=\frac{1}{2} \sum_{i} c_{i} z_{i}^{2}
$$


Here $c_{i}$ is the concentration of the $i$ th species of ions, and $z_{i}$ is the valency of the ion.

The ionic strength of the dissolved salts in water is a very important aspect of this project, for a high ionic strength causes a large current flow through the suspension, which is undesirable. For this reason the water chemistry must be taken into account

Smoluchowski's theory has been greatly extended by many investigators (see Hunter, 1987) to relax the assumptions of a thin double layer and to take into account the hindered motion resulting from particle-particle interactions. Kozak and Davis (1989a,b) analyzed the effects of the electrical double layer thickness and hydrodynamic interactions, and made measurements of the motion of dense colloidal suspensions (Kozak and Davis, 1990). The sedimentation of concentrated suspensions is much more complicated than the motion analyzed by Smoluchowski.

Through a grant provided by the U.S. Bureau of Mines, Sauer and Davis (1994) explored the electrophoretic sedimentation of mining and mineral industry colloidal suspensions. They obtained colloidally contaminated samples from an impoundment at the mine site in Centralia, WA, and showed that the dilute suspensions encountered there could be treated electrokinetically, using a small electrokinetic cell. The current research is an outgrowth of that earlier study.

\section{RESULTS}

Two sets of samples were obtained from Centralia, Washington. The first samples obtained were from the Centralia Steam Plant. These samples were water mixed with coal particles from the CPRO (coal pile runoff) ditch located adjacent to the power plant. This water is presently being treated with coagulant chemicals in very small dosages and then run through a series of impoundments (settling ponds). The ponds are drained and bypassed when they become full and the sediments are dried and burned or used for fill in reclamation of the mine site. Upon analysis it was determined that this water was only very lightly contaminated, and with particles larger than colloidal size. The particles gravitationally settled out over a period of about a week. Further investigation revealed that this was not where the coal was initially washed. The primary washing occurs at the mine.

A second set of samples was obtained, this time from the Centralia Mining Company of Centralia, Washington. This water is used to wash the coal during beneficiation for removal of fine coal dust and clay particles. It is then sent to a thickener and treated with coagulants before being sent through a series of settling ponds, which are self-contained impoundments. The clean water is then returned to the process loop.

Measurements of the colloidal properties of the fine particles indicated that the second set of samples were similar to those in the colloidally-contaminated water studied by Sauer and Davis. Table 1 lists the properties of the suspension obtained from the coal-washing facility, and Table 2 summarizes the particle size data obtained using a Horiba CAPA-500 Particle Analyzer. The mean diameter of $1.83 \mu \mathrm{m}$ indicates that the particles were, indeed, colloidal. The electrophoretic mobilities ( $U_{E}=v_{E} / E$ ) of the particles were measured with a Rank Brothers Mark $I$ Microelectrophoresis apparatus, and the results are presented in 
Table 3. Once the water chemistry is determined, the zeta potentials can be determined from the data of Table 3.

Table 1. Suspension Characteristics

Volume Average Diameter $(\mu \mathrm{m})$

1.83

Solids by Weight (\%)

1.32

Water $\mathrm{pH}$

7.62

Conductivity $(\mathrm{S} / \mathrm{cm})$

$2.01 \times 10^{-3}$

Table 2. Particle Size Statistics

Mean Diameter $(\mu \mathrm{m})$

1.83

Standard Deviation

1.202

Sample Variance

1.45

Size Range $(\mu \mathrm{m})$

0 to 6

Minimum Diameter $(\mu \mathrm{m})$

$-0.10$

Maximum Diameter $(\mu \mathrm{m})$

$\sim 5.7$

Table 3. Electrophoretic Mobilities of 39 Particles tested.

Mean Particle Mobility $\left(\mathrm{m}^{2} / \mathrm{V}-\mathrm{s}\right)$

Standard Deviation

Sample Variance

Minimum Mobility ( $\left.\mathrm{m}^{2} / \mathrm{V}-\mathrm{s}\right)$

Maximum Mobility $\left(\mathrm{m}^{2} / \mathrm{V}-\mathrm{s}\right)$
$-2.33 * 10^{-8}$

$3.89 * 10^{-9}$

$1.52 * 10^{-17}$

$-1.60 * 10^{-8}$

$3.04 * 10^{-8}$

A Plexiglas sedimentation tank was constructed to perform sedimentation experiments with the samples from Centralia. Figure 1 is a schematic of the apparatus. Two arrangements for electrically wiring the sedimentation cell have been considered for this project. Both use the same $38 \mathrm{~cm}$. square Plexiglas tank. The anode is stationary on the bottom of the tank, and the cathode at the top is adjustable; it also positions probes used to measure the potential distribution of the electrical field within the cell. An optical device for determining the sedimentation interface will be installed in future experiments.

$-4-$ 


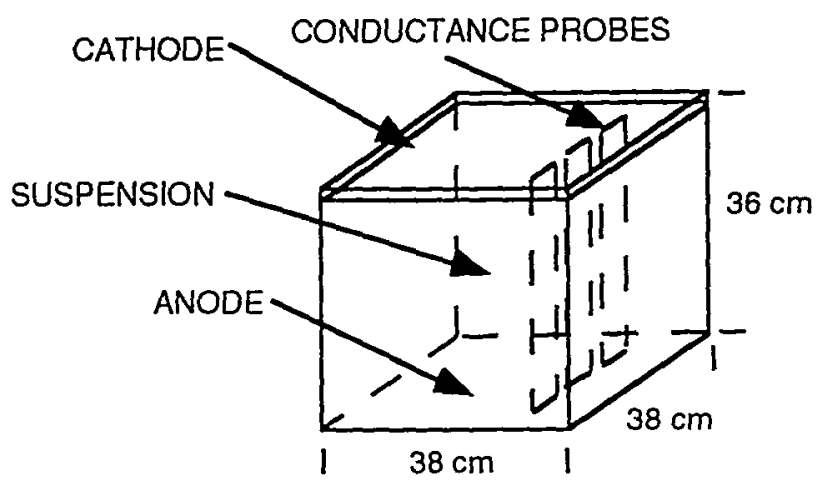

Figure 1. A schematic of the sedimentation cell.

The first of the two setups utilized carbon fiber electrodes with gold-plated lead wires attached to the power supply. It also employed nine tubular probes, also with gold plated leads, which would return the electrical field information to a computer data acquisition system. The electrode materials were chosen because of their relatively inert properties. A test of this setup revealed some of its inadequacies and gave reason to search for another type of electrode system design.

The second setup utilizes solid sheets of stainless steel as electrodes with stainless steel lead wires welded to the electrode. It also employs nine probes this time printed on circuit boards. The probe leads are again gold plated. The same data acquisition system is used with this setup.

The actual experiments were done by positioning the electrodes five and one half inches apart. This allowed a five gallon volume of the sample to be used for each test. A power supply is used in conjunction with a voltmeter and an ammeter to supply current to the cell. The optical device traverses the tank to determine the location of the sedimentation interface, while the probes return the electrical field information to the computer's data acquisition system.

\section{DISCUSSION}

Testing of the first setup achieved encouraging visible results; the agglomeration and the sedimentation interface were obvious to the eye. One problem was also immediately visible. Gas evolved at the electrodes. This gas was the result of applying excessive voltage to the system, causing electrolysis to occur. When the cell was dismantled the electrode fibers were clogged, and the lead wires were corroded; one of the wires had become separated from the electrode. The probe leads were also corroded. Alter the system was dismantled it was apparent that the carbon fiber was too brittle and expensive to continue using.

Before running any experiments in the second setup the sample was further characterized by obtaining cyclic voltammograms. This was done to indicate the presence 
of an electrochemical reaction, which is indicated by a significant increase in current with a slight voltage increase. This would determine the voltages where the experiment could be run without a reaction occurring (e.g., corrosion).

The second setup also appeared to have successfully initiated sedimentation until circuitry problems began to arise. At first it was being run at constant voltage to avoid gas evolution. This became a problem, however; because the current decreased as the resistance within the system increased. The increased resistance was again caused by the growing sediment layer on the anode.

Therefore, the experiment was switched to run at constant current, allowing voltage to rise as resistance increased. The problem with this mode of operation is that the voltage may again increase and initiate gas evolution.

In the end, setup two had to be shut down because the circuit had built up such a high resistance that the power supply could no longer provide the necessary voltage required for the constant current operation. A 2500 volt power supply is, at present, being fitted for continued runs with setup two. Also, at this time, plans for a new setup with a moving electrode and a cleaning mechanism, that would remove buildup from the electrode, are being made.

These preliminary studies have provided the information needed to improve the design of the system.

\section{LITERATURE CITED}

Hunter, R.J. (1987). Foundations of Colloid Science, Volumes I and II, Oxford University Press, Oxford.

Kozak, M.W., and Davis, E.J. (1989a). Electrokinetics of Concentrated Suspensions and Porous Media, Part 1: Thin Electrical Double Layers, J. Colloid Interface Sci. 127, 497-510.

Kozak, M.W., and Davis, E.J. (1989b) Electrokinetics of Concentrated Suspensions and Porous Media, Part 2: Moderately Thick Electrical Double Layers, J. Colloid Interface Sci. 129, 166-174.

Kozak, M.W., and Davis, E.J. (1990). Moving Boundary Electrophoresis of Concentrated Suspensions and Electroosmosis in Porous Media, Langmuir 6, 1585-1590.

Sauer, J.E., and Davis, E.J. (1994). Electrokinetically Enhanced Sedimentation of Colloidal Contaminants, Environ. Sci. Technol. 28, 737-745. 
I wish to say that I enjoyed my internship experience thoroughly, the work was absorbing and related well to my interests in the environmental engineering aspects of coal mining and power production. The people at University of Washington were all wonderful and contributed to what was a very positive preview of graduate school. I not only was able to apply my environmental engineering education, but also learned a great deal about chemical engineering. I am even considering the addition of a course in physical chemistry to next semester's schedule.

Even though this research is only in it's infancy I feel that the result will make using an electrical field to achieve separation of colloidal suspensions, a viable alternative to using chemical coagulants as a treatment strategy.

\section{FURTHER ACKNOWLEDGMENTS}

I wish to thank the Department of Energy, the UCR Internship Program, and ORISE for their support. I also wish to thank the University of Washington, Dr. E. James Davis, Tim Johnson and the rest of the Davis Group; Chris Aardahl, John Widmann, Matt Tadd, and Rheinhard Verhing. I also wish to acknowledge the kind assistance of Tom Emrich; at Pacificorp Power Supply, and Bart Hyita and Gary Yoakam, at Centralia Mining Company. I would also like to thank my husband and family for their love and support while I have been away from home. A special thanks also to Angie Palmer formerly of ORISE. 